\title{
Impact of Synergy Model application on Patients with Acute Coronary Syndrome Outcomes
}

\author{
Azza Salman Ahmed, Mona Aly Mohammed \& Hassan Ahmed Hassanin. \\ Nursing Supervisor at Medical Units, Sohage University Hospital, Assuit University, Egypt. \\ Lecturer in Critical Care Nursing Department, Faculty of Nursing, Assuit University, Egypt. \\ Professor of Internal Medicine, Faculty of Medicine, Sohage University, Egypt.
}

\begin{abstract}
Synergy model gives nurses a common language for a definition and relation between patients and nurse's needs, so patient with acute coronary syndrome need immediate nurses knowledge in coronary care unit. Aim: the aim of this study is to investigate the impact of Synergy model application on patients with Acute Coronary Syndrome outcomes. Design: a quasi-experimental research design is used in this study. Setting: This study was carried out in the coronary care unit at Sohage University Hospital. Subjects: Sixty critically ill adult patients who are admitted to the previously mentioned setting, and 12 (twelve) number of nurses in coronary care unit. Tool: Synergy model tool which include two parts, Part I: Patients' characteristics, (Stability, Resiliency and Resource availability ) Part two: Nurse-Competence (Advocacy moral agency, Caring practice and Clinical judgment). Results: Findings of the current study revealed statistical significance deference in both patient's needs and nurse's knowledge according to Synergy model for level I, level 3, level 5 which determine quality of nurses and the behavior toward the patient. In this study there are highly statistical significance different according to patients needs and nurses knowledge With $(\mathrm{P}=0.000 *),(0.004) *$. Conclusion: The synergy model outlines that when patients' characteristics and nurses competencies synergize, optimal patient outcomes are achieved. As the patient is primary focus, optimal outcomes are defined as what patients themselves acknowledged as important.
\end{abstract}

Key words Synergy model, acute coronary syndrome\& patient outcomes.

\section{Introduction}

Synergy model as a professional care model expresses a framework that clears relationship of nurses with patients, other nurses and others in the health care team. This model makes a common language for nurses in order to define and make relationship between patient's needs. This model is a perfect framework for organizing function of taking care of the patient in the line of health care system (Barbosa et al., 2012).

The main content of this model indicated that needs or characters of the patient's and their families are in interaction and can help in providing effectiveness of the care with the abilities and characteristics of the nurses. Synergy is conducted when the patient's needs and characteristics, clinical unit or system are in coordination with the nurses abilities and talents. Providing maximum care is improving by coordination between patient's characteristics (needs) and nurses features (competencies). According to this model when patient's characteristics and nurses competencies are together, patient's meet their expectations in an appropriate level (Peterson et al., 2009).

By using synergy model, since the patient has biological, mental, social and spiritual aspects that emerge in different stages of growth, the whole of the patient (body, mind and spirit) is taken into consideration. There is coordination between patient, family and units in order to provide necessary background for nurse-patient relationship

(Kuriakosa, 2008).

\section{Aim of the Study}

The aim of the study was to determine the impact of synergy model application on patients with Acute coronary syndrome outcomes.

\section{Patients and method}

\section{Research Design}

Quasi-experimental research design was used to conduct this study.

Hypotheses

patients with Acute Coronary Syndrome who are utilizing synergy model as a framework in the professional care exhibit more improved outcomes than those who are not utilized it.

Settings of the study: The study was carried out in the coronary care unit at Sohage University Hospital.

\section{Sample}

A convenient sample of 60 critically ill adult patients who were admitted to the coronary care unit. The 
subjects were assigned into two equal groups (control group and study group, 30 patients each)

All available, 12 (twelve) number of nurses in the study period in coronary care unit.

Inclusion criteria: All adult patients admitted to the coronary care unit, diagnosed with acute coronary syndrome(Myocardial infarction, unstable angina).

Exclusion criteria: the patients with cardiac complications, Kidney disease, Liver disease, History of malignancies excluded from the study.

\section{Study Tool: "Synergy model tool"}

This model was applicator to collect the study data; it was developed by the researcher and translated into Arabic languages after passing through an extensive and relevant review of literature (American Association of Critical Nursing, 2006). It included two parts:

Part one: data related to the patients' characteristics

Socio- demographic data that included age, sex, and level of education, marital status and clinical data (Types of acute coronary syndrome, Risk factors).

Patient's characteristics that included:( stability, resiliency and resources availability )

Part two: data related to the nurses characteristics:

Socio- demographic data that included age, educational level, and material status.

Nursing competency that included advocacy moral agency, caring practice and clinical judgment

\section{Methods}

An Official permission letter to conduct the study was obtained from the hospital responsible authorities in the coronary care unit.

Protection of human rights (ethical considerations): consent was obtained from the nurses and the patients in the coronary care unit. The investigator emphasized that the participation is voluntary and the confidentiality and anonymity of the subjects will be assured through coding the data. Subjects were assured can withdraw from the study at any time without any rational.

The model tested for content validity by Jury of 5 expertise from the field of medical cardiologist staff ( 2 professors and 1 assistant professor) and nursing educators (2 professors).

A pilot study was conducted on 6 patients to test the feasibility and clarity of the study, analysis of the pilot study defined the modification required, and the necessary modifications were done and study subjects were excluded from the actual study.

The data collection covered a period of one year starting from September 2012 till the end of September 2013.

This study was implemented throughout three phases: Assessment, Implementation and Evaluation phase.
The assessment phase for patients and nurses: The control group assessed by the researcher related literature.

The study group was assessed by the researcher using application of Synergy model tool.

The researcher was interviewing the patient individually to assess patient characterizes sheet (question) according to Synergy model about patient with experience of an acute coronary syndrome for answering all its questions. Which include: The researcher initial line of communication by introduce of herself, patient instructions for exercise, activities of daily living, nutrition, risk factor and information about discharge home care for taking medication as doctor order according to patient condition which interview take about 6-8 session individuality and each time take 5-7 minutes.

\section{Implementation and evaluation phase} As regard the patients

General objectives line of communication with the patients' individuality; the nature and purpose of the study was applicator to improve their outcomes.

Teaching strategies included figures, and studies presented to the patients to practice, and the place of teaching in the coronary care units.

Group 1(Control group) patients with acute coronary syndrome received the routine hospital care according patient condition about medication and nursing care.

Group (II) : (Study group) patients with acute coronary syndrome who were application by using part (I) : according to Synergy model tool that included the following: *stability (Response to pain relief, consideration of death and thoughts of experiencing chest pain/discomfort); *resiliency (Ability to chest pain, level of knowledge and method used to control symptoms after cardiac episodes) and *resource availability (Pain or discomfort during an emergency situation, sign and symptoms related to cardiac problem and knowledge of medications taken in case of chest discomfort) * included (10) questions about patients experience an acute coronary syndrome for answering all questions.

As regard to the nurse

training program by using synergy model to teach them the skills and knowledge for caring the patient with acute coronary syndrome (pre and post implementation of the training program). It consists of four sessions:

The first session included information about nursing care of patient with acute myocardial infarction.

The second session included nursing care of patient with unstable angina.

The third session included information about how to apply the synergy model in critical care unit to assess the nurse's competencies according to model. 
The fourth session included information about nursing standard (policies) in critical care unit.

The duration of each session about 20-30 minutes. At the end of each session discussion and feedback were made.

Teaching strategies included presenting figures and studies to nurses about procedures of practice and knowledge.

A scoring system for knowledge and skills presenting translating synergy rating scores by considering both the category score (patient character and nurse competencies) from 1 to 5 with 1 indicating the lowest quality of care and 5 indicating the highest quality of care. Synergy rating are based on nursing time needed to complete a task, emotional and physical energy expenditure required, expertise required, frequency of tasks and interventions, and follow-up assessment related to specific task, rating for all categories summed up to obtain a total synergy rating score for each nurses ranging from I to 12 .

A scoring system for synergy rating score by measuring level of nurse's knowledge according to (level 1- level 3- level 5). The Synergy model of nursing is an American practice designed to pair the needs of the patient and their family with the strengths of the nurse providing care. For instance, if a patient comes from a different culture than the nurse, the nurse who is an expert (level 5) in the Response to Diversity competency would be able to evaluate his or her own biases and beliefs, respond to and anticipate the needs of the patient. The nurse must be able to integrate cultural differences into the plan of care, including alternative therapies. In this way, all the needs of the patient are met, and the nurse has established a working relationship with the patient and family.

Rating for all 5 categories summed up to obtain a total synergy rating score for each patient ranging from 1 to 30. A scoring system for synergy rating score by measuring level characteristics for patients according to (level 1- level 3- level 5).

Statistical analysis

Data entry and data analysis were done using SPSS version 19 (Statistical Package for Social Science). Data were presented as number, percentage, mean, standard deviation. Chi-square test was used to compare between qualitative variables. Independent t-test was used to compare quantitative variables. Pvalue considered statistically significant when $\mathrm{P}<$ 0.05 . 


\section{Results}

Table (1) Comparison between study and control group of the patient with ACS according to the socio-demographic data, presence of risk factors, and types of acute coronary syndrome.

\begin{tabular}{|c|c|c|c|c|c|}
\hline \multirow{2}{*}{ Variables } & \multicolumn{2}{|c|}{ study group $(n=30)$} & \multicolumn{2}{|c|}{ control group $(n=30)$} & \multirow{2}{*}{ P-value } \\
\hline & No. & $\%$ & No. & $\%$ & \\
\hline \multicolumn{5}{|l|}{ Age } & \multirow{4}{*}{0.258} \\
\hline$<50$ years & 9 & 30.0 & 7 & 23.3 & \\
\hline $50-55$ years & 8 & 26.7 & 4 & 13.3 & \\
\hline$>55$ years & 13 & 43.3 & 19 & 63.3 & \\
\hline Mean \pm SD & \multicolumn{2}{|c|}{$52.37 \pm 8.14$} & \multicolumn{2}{|c|}{$57.73 \pm 9.20$} & $0.026 *$ \\
\hline \multicolumn{5}{|l|}{ Sex } & \multirow{3}{*}{0.606} \\
\hline Male & 16 & 53.3 & 14 & 46.7 & \\
\hline Female & 14 & 46.7 & 16 & 53.3 & \\
\hline \multicolumn{5}{|l|}{ Educational level } & \multirow{5}{*}{0.801} \\
\hline Illiterate & 19 & 63.3 & 17 & 56.7 & \\
\hline Primary & 4 & 13.3 & 5 & 16.7 & \\
\hline Secondary & 5 & 16.7 & 4 & 13.3 & \\
\hline University & 2 & 6.7 & 4 & 13.3 & \\
\hline \multicolumn{6}{|l|}{ Risk factors } \\
\hline Hypertension & 13 & 43.3 & 8 & 26.7 & 0.176 \\
\hline DM & 10 & 33.3 & 14 & 46.7 & 0.292 \\
\hline Obesity & 6 & 20.0 & 4 & 13.3 & 0.488 \\
\hline Smoking & 8 & 26.7 & 13 & 43.3 & 0.176 \\
\hline \multicolumn{6}{|l|}{ Types of ACS } \\
\hline Myocardial infarction & 17 & 56.7 & 19 & 63.3 & \multirow{2}{*}{0.598} \\
\hline Unstable angina & 13 & 43.3 & 11 & 36.7 & \\
\hline
\end{tabular}

- Independent samples t-test

Chi-square test $*$ Statistical significant difference $(P<0.05)$

Table (2): Comparison between study and control groups as regards the stability with the experience of an ACS situation.

\begin{tabular}{|c|c|c|c|c|c|c|}
\hline \multirow{2}{*}{\multicolumn{2}{|c|}{ Variables }} & \multicolumn{2}{|c|}{ Study group $(n=30)$} & \multicolumn{2}{|c|}{ control group $(n=30)$} & \multirow{2}{*}{ P-value } \\
\hline & & No. & $\%$ & No. & $\%$ & \\
\hline \multirow[t]{5}{*}{ Level 1} & \multicolumn{5}{|l|}{ Response to pain relief } & \multirow{5}{*}{0.127} \\
\hline & Pain decreased & 23 & 76.7 & 16 & 53.3 & \\
\hline & Pain did not decrease & 4 & 13.3 & 4 & 13.3 & \\
\hline & Pain increased & 2 & 6.7 & 9 & 30.0 & \\
\hline & No pain relief measure given & 1 & 3.3 & 1 & 3.3 & \\
\hline \multirow[t]{3}{*}{ Level 3} & \multicolumn{5}{|l|}{ Consideration of death } & \multirow{3}{*}{$0.001 *$} \\
\hline & Yes & 10 & 33.3 & 25 & 83.3 & \\
\hline & No & 20 & 66.7 & 5 & 16.7 & \\
\hline \multirow[t]{4}{*}{ Level 5} & Thoughts of experiencing ch & discom & & & & \multirow{4}{*}{$0.001 *$} \\
\hline & Yes, often & 20 & 66.7 & 5 & 16.7 & \\
\hline & Yes, sometimes & 5 & 16.7 & 10 & 33.3 & \\
\hline & No & 5 & 16.7 & 15 & 50.0 & \\
\hline
\end{tabular}

- Independent samples t-test $\quad$ Chi-square test $\quad *$ Statistical significant difference $(\mathrm{P}<0.05)$ 
Table (3) : Comparison between study and control groups regarding the resiliency with the experience of an ACS situation.

\begin{tabular}{|c|c|c|c|c|c|c|}
\hline \multirow{2}{*}{\multicolumn{2}{|c|}{ Variable }} & \multicolumn{2}{|c|}{ Study group $(n=30)$} & \multicolumn{2}{|c|}{ Control group $(n=30)$} & \multirow[t]{2}{*}{ P-value } \\
\hline & & No. & $\%$ & No. & $\%$ & \\
\hline \multirow[t]{4}{*}{ Level 1} & \multicolumn{5}{|l|}{ Ability to bear chest pain } & \multirow{4}{*}{$0.002 *$} \\
\hline & Very well & 3 & 10.0 & 15 & 50.0 & \\
\hline & Fairly well & 13 & 43.3 & 10 & 33.3 & \\
\hline & Poorly well & 14 & 46.7 & 5 & 16.7 & \\
\hline \multirow[t]{3}{*}{ Level 3} & \multicolumn{5}{|c|}{ Level of knowledge in response to emergency situation } & \multirow{3}{*}{0.071} \\
\hline & Yes & 19 & 63.3 & 12 & 40.0 & \\
\hline & No & 11 & 36.7 & 18 & 60.0 & \\
\hline \multirow[t]{5}{*}{ Level 5} & Methods used to control $\mathrm{s}$ & toms a & rdiac & les & & \multirow{5}{*}{0.212} \\
\hline & None & 8 & 26.7 & 2 & 6.7 & \\
\hline & Alternative medical systems & 16 & 53.3 & 19 & 63.3 & \\
\hline & Mind-body interventions & 3 & 10.0 & 5 & 16.7 & \\
\hline & Biologically based treatments & 3 & 10.0 & 4 & 13.3 & \\
\hline
\end{tabular}

- Independent samples $t$-test $\quad$ Chi-square test $\quad *$ Statistical significant difference $(P<0.05)$

Table (4): Comparison between study and control groups as regard the knowledge of their illness.

\begin{tabular}{|c|c|c|c|c|c|}
\hline \multirow[t]{2}{*}{ Variables } & \multicolumn{2}{|c|}{ Study group $(n=30)$} & \multicolumn{2}{|c|}{ Control group $(n=30)$} & \multirow[t]{2}{*}{ P-value } \\
\hline & No. & $\%$ & No. & $\%$ & \\
\hline \multicolumn{5}{|c|}{ Pain or discomfort during an emergency situation } & \multirow{6}{*}{$0.039 *$} \\
\hline \multicolumn{5}{|l|}{ Area of pain or discomfort } & \\
\hline In the chest & 26 & 86.7 & 19 & 63.3 & \\
\hline In the neck or jaw & 0 & 0.0 & 0 & 0.0 & \\
\hline In the arm or shoulder & 4 & 13.3 & 6 & 20.0 & \\
\hline On the back & 0 & 0.0 & 5 & 16.7 & \\
\hline \multicolumn{5}{|l|}{ Atypical symptoms of ACS } & \multirow{5}{*}{0.230} \\
\hline Heart or epigastria discomfort & 19 & 63.3 & 15 & 50.0 & \\
\hline Sweating & 4 & 13.3 & 2 & 6.7 & \\
\hline Shortness of breath & 7 & 23.3 & 13 & 43.3 & \\
\hline Syncope of any feeling of faintness & 0 & 0.0 & 0 & 0.0 & \\
\hline \multicolumn{6}{|c|}{ Signs and Symptoms related to cardiac problem } \\
\hline Yes & 14 & 46.7 & 16 & 53.3 & \multirow{2}{*}{0.606} \\
\hline No & 16 & 53.3 & 14 & 46.7 & \\
\hline \multicolumn{6}{|l|}{ Activity during pain onset } \\
\hline Resting & 22 & 73.3 & 25 & 83.3 & \multirow{2}{*}{0.347} \\
\hline Working & 8 & 26.7 & 5 & 16.7 & \\
\hline
\end{tabular}

- Independent samples $t$-test $\quad$ Chi-square test $*$ Statistical significant difference $(P<0.05)$

Table (5): Personal characteristics of the studied nurses.

\begin{tabular}{|c|c|c|}
\hline & No. $(n=12)$ & $\%$ \\
\hline \multicolumn{3}{|l|}{ Age: (years) } \\
\hline Mean \pm SD & \multicolumn{2}{|c|}{$25.75 \pm 3.14$} \\
\hline Range & \multicolumn{2}{|c|}{$22.0-32.0$} \\
\hline \multicolumn{3}{|l|}{ Marital status } \\
\hline Single & 3 & 25 \\
\hline Married & 9 & 75 \\
\hline \multicolumn{3}{|l|}{ Qualification } \\
\hline Nursing Diploma & 11 & 91.7 \\
\hline Nursing Technical Institute & 1 & 8.3 \\
\hline
\end{tabular}


Table (6): Comparison between nurse's knowledge about caring practices in nurses 'competence in patient with acute coronary syndrome.

\begin{tabular}{|c|c|c|c|c|c|}
\hline \multirow{2}{*}{ Caring practices } & \multicolumn{2}{|c|}{ Pre $(n=12)$} & \multicolumn{2}{|c|}{ Post $(n=12)$} & \multirow{2}{*}{ P value } \\
\hline & No. & $\%$ & No & $\%$ & \\
\hline \multicolumn{5}{|c|}{ B1: Practice needs required by the patient's heart when he entered } & \multirow{3}{*}{-- } \\
\hline Yes & 12 & 100.0 & 12 & 100.0 & \\
\hline No & 0 & 0.0 & 0 & 0.0 & \\
\hline \multicolumn{6}{|l|}{ B2:If yes } \\
\hline Answer questions. & 2 & 16.7 & 5 & 41.7 & 0.371 \\
\hline Implementation demand & 5 & 41.7 & 4 & 33.3 & 1.001 \\
\hline Reassure the family of the patient about his condition & 6 & 50.0 & 7 & 58.3 & 1.001 \\
\hline \multicolumn{5}{|c|}{ B3: Procedure that followed in critical care enough } & \multirow{3}{*}{1.001} \\
\hline Yes & 11 & 91.7 & 12 & 100.0 & \\
\hline No & 1 & 8.3 & 0 & 0.0 & \\
\hline \multicolumn{5}{|c|}{ B4: Making caring practice to improve patient condition } & \multirow{3}{*}{0.478} \\
\hline Yes & 10 & 83.3 & 12 & 100.0 & \\
\hline No & 2 & 16.7 & 0 & 0.0 & \\
\hline \multicolumn{6}{|l|}{ B5: If yes } \\
\hline Give medication & 4 & 40.0 & 8 & 66.7 & 0.391 \\
\hline Maintain patient environment clean & 2 & 20.0 & 3 & 25.0 & 1.001 \\
\hline Nutrition of patient & 4 & 40.0 & 6 & 50.0 & 0.691 \\
\hline
\end{tabular}

- Independent samples t-test $\quad$ Chi-square test $\quad *$ Statistical significant difference $(P<0.05$

Table (7) Comparison between nurses' knowledge about clinical judgment in nurses' competences in patients with acute coronary syndrome.

\begin{tabular}{|c|c|c|c|c|c|}
\hline \multirow{2}{*}{ Clinical judgment } & \multicolumn{2}{|c|}{ Pre $(n=12)$} & \multicolumn{2}{|c|}{ Post $(n=12)$} & \multirow{2}{*}{ P-value } \\
\hline & No. & $\%$ & No. & $\%$ & \\
\hline \multicolumn{5}{|l|}{ B1:Implementation of patient order } & \multirow{3}{*}{--} \\
\hline Yes & 12 & 100.0 & 12 & 100.0 & \\
\hline No & 0 & 0.0 & 0 & 0.0 & \\
\hline \multicolumn{6}{|l|}{ B2:If yes } \\
\hline patient monitor & 8 & 66.7 & 12 & 100.0 & 0.093 \\
\hline give medication & 7 & 58.3 & 6 & 50.0 & $\mathbf{0 . 6 8 2}$ \\
\hline Laboratory investigation & 9 & 75.0 & 9 & 75.0 & 0.400 \\
\hline make ECG & 6 & 50.0 & 7 & 58.3 & 0.682 \\
\hline \multicolumn{5}{|l|}{ B3:present policy in critical care } & \multirow{3}{*}{$0.001 *$} \\
\hline Yes & 1 & 8.3 & 12 & 100.0 & \\
\hline No & 11 & 91.7 & 0 & 0.0 & \\
\hline \multicolumn{5}{|l|}{ B4:If yes } & \multirow{5}{*}{--} \\
\hline Commitment time of visit & 1 & 100.0 & 4 & 33.3 & \\
\hline Commitment for calm & 0 & 0.0 & 3 & 25.0 & \\
\hline Follow doctor advise & 0 & 0.0 & 5 & 41.7 & \\
\hline explain how to prevent & 0 & 0.0 & 7 & 58.3 & \\
\hline \multicolumn{5}{|c|}{ B4:make procedure for improve the policy } & \multirow{3}{*}{0.093} \\
\hline Yes & 0 & 0.0 & 4 & 33.3 & \\
\hline No & 12 & 100.0 & 8 & 66.7 & \\
\hline \multicolumn{5}{|l|}{ B5:If yes } & \multirow{4}{*}{--} \\
\hline advise the patient and how to prevent & 0 & 0.0 & 2 & 50.0 & \\
\hline collaboration with other team & 0 & 0.0 & 1 & 25.0 & \\
\hline answer patient questions & 0 & 0.0 & 3 & 75.0 & \\
\hline
\end{tabular}

- Independent samples t-test 
Table (8): Comparison between nurses' knowledge about advocacy moral agency in nurses' competence inpatient with acute coronary syndrome

\begin{tabular}{|c|c|c|c|c|c|}
\hline \multirow{2}{*}{ Advocacy and moral agency } & \multicolumn{2}{|c|}{$\operatorname{Pre}(n=12)$} & \multicolumn{2}{|c|}{$\operatorname{Post}(n=12)$} & \multirow{2}{*}{ P-value } \\
\hline & No. & $\%$ & No. & $\%$ & \\
\hline \multicolumn{5}{|l|}{ B1 Patient privacy during nursing care } & \multirow{3}{*}{--} \\
\hline Yes & 12 & 100.0 & 12 & 100.0 & \\
\hline No & 0 & 0.0 & 0 & 0.0 & \\
\hline \multicolumn{6}{|l|}{ B2: If yes } \\
\hline Respect patient privacy & 6 & 50.0 & 9 & 75.0 & 0.400 \\
\hline Not to reveal his genitalia when detected and work ECG. & 10 & 83.3 & 10 & 83.3 & -- \\
\hline \multicolumn{5}{|c|}{ B3: Health education to the patient prior to their release from care } & \multirow{3}{*}{0.217} \\
\hline Yes & 9 & 75.0 & 12 & 100.0 & \\
\hline No & 3 & 25.0 & 0 & 0.0 & \\
\hline \multicolumn{6}{|l|}{ B4: If yes } \\
\hline Important of patient follow up & 3 & 33.3 & 5 & 41.7 & 1.001 \\
\hline Explain patient procedure & 6 & 66.7 & 8 & 66.7 & 1.001 \\
\hline Present to hospital during emergency situation & 2 & 22.2 & 3 & 25.0 & 1.001 \\
\hline
\end{tabular}
- Independent samples t-test
Chi-square test
* Statistical significant difference $(P<0.05)$

Table (9): Rating synergy model score for patients' characteristics (Stability, Resiliency and Resource availability).

\begin{tabular}{|c|c|c|c|c|c|}
\hline \multirow{2}{*}{ Variables } & \multicolumn{2}{|c|}{ Control group $(n=30)$} & \multicolumn{2}{|c|}{ Study Group $(n=30)$} & \multirow{2}{*}{ P-value } \\
\hline & No. & $\%$ & No. & $\%$ & \\
\hline \multicolumn{5}{|l|}{ Stability } & \multirow{3}{*}{$0.004 *$} \\
\hline Least & 23 & 76.7 & 12 & 40.0 & \\
\hline Most & 7 & 23.3 & 18 & 60.0 & \\
\hline \multicolumn{5}{|l|}{ Resiliency } & \multirow{3}{*}{$0.000 *$} \\
\hline Least & 24 & 80.0 & 10 & 33.3 & \\
\hline Most & 6 & 20.0 & 20 & 66.7 & \\
\hline \multicolumn{5}{|l|}{ Resource availability } & \multirow{3}{*}{ 0.000* } \\
\hline Least & 21 & 70.0 & 5 & 16.7 & \\
\hline Most & 9 & 30.0 & 25 & 83.3 & \\
\hline
\end{tabular}

- Independent samples $t$-test

Chi-square test * Statistical significant difference $(P<0.05)$

Table (10): Rating synergy model Score for nursing competency (Advocacy moral agency, Caring practice and Clinical judgment ).

\begin{tabular}{|c|c|c|c|c|c|}
\hline \multirow[t]{2}{*}{ Variables } & \multicolumn{2}{|c|}{$\begin{array}{l}\text { Pre-test } \\
(n=12)\end{array}$} & \multicolumn{2}{|c|}{$\begin{array}{c}\text { Post-test } \\
(n=12)\end{array}$} & \multirow[t]{2}{*}{ P-value } \\
\hline & No. & $\%$ & No. & $\%$ & \\
\hline \multicolumn{5}{|l|}{ Advocacy and moral agency: } & \multirow{3}{*}{$0.001 *$} \\
\hline Least & 9 & 75.0 & 1 & 8.3 & \\
\hline Most & 3 & 25.0 & 11 & 91.7 & \\
\hline \multicolumn{5}{|l|}{ Caring practice: } & \multirow{3}{*}{$0.013 *$} \\
\hline Least & 8 & 66.7 & 2 & 16.7 & \\
\hline Most & 4 & 33.3 & 10 & 83.3 & \\
\hline \multicolumn{5}{|l|}{ Clinical judgment: } & \multirow{3}{*}{$0.030 *$} \\
\hline Least & 11 & 91.7 & 5 & 41.7 & \\
\hline Most & 1 & 8.3 & 7 & 58.3 & \\
\hline
\end{tabular}


Table (1) : presents the mean age in the study and control group $(52.37 \pm 8.14,57.73 \pm 9.20$ years $)$ respectively, with statistical significant difference $(\mathrm{P}=0.026 *)$. Moreover, $53.3 \%$ of the sample in the study group were male versus $46.7 \%$ in control group with no significant difference $(\mathrm{P}=0.606)$. As for the risk factors there were $43.3 \%$ of the study group versus $26.7 \%$ in the control group had hypertension, while, $33.3 \%$ in the study group versus $46.7 \%$ in the control group experienced diabetes mellitus, and $20.0 \%$ in the study group versus 13.3 $\%$ in the control group suffered obesity. Furthermore, $26.7 \%$ of the sample in the study group versus $43.3 \%$ in the control group was smoker, and $56.7 \%$ in study group versus $63.3 \%$ in the control group experienced myocardial infarction, while $43.3 \%$ in study group versus $36.6 \%$ in the control group had unstable angina.

Table (2) : indicates the response to pain relief during an ACS situation, the participants in this study may experience chest pain They received pain relief medications; it was found that the pain was decreased in $76.7 \%$ of the study group versus $53 \%$ of the control group, but $13.3 \%$ of the study and control group did not do so. However, the pain in the current study was increased in $6.7 \%$ of the study group versus $30 \%$ in control group. While no pain measurements were performed for the remaining 3.3 $\%$ in study and control group.

As for the consideration of death, the same table shows that $33.3 \%$ of the study versus $83.3 \%$ in the control group said "yes', while $66.7 \%$ versus $16.7 \%$ of the study and control group said "no", with statistical significant difference $(\mathrm{P}=0.000 *)$.

Regarding thoughts of experiencing chest pain/discomfort, it was found that $16.7 \%$ in the study group versus $50.0 \%$ in the control group expressed that they did not thought that they would experience chest pain or discomfort, although $16.7 \%$ in study group versus $33.3 \%$ in the control group said sometimes they did so, with statistical significant difference $(\mathrm{P}=0.000 *)$.

Table (3) : reveals ability to bear chest pain (Level $1)$, the ability to cope with chest pain was fairly divided among the participants as follows $46.7 \%$ of the sample in the study groupversus $16.7 \%$ in control group coped poorly to chest pain, while $43.3 \%$ in the study group versus $3 \%$ in control group coped fairly well, and $10.0 \%$ in the study group versus $50.0 \%$ in the control group coped very well with statistical significant difference $(\mathrm{P}=0.002 *)$. The support system and the individual's psychological capacity to tolerate pain may have played a role in the outcome of the patient's ability to bear chest pain.

In relation to the Level of knowledge in response to emergency situation (Level 3), results of the current study show that from the 30 participants $19(63.3 \%)$ in the study group versus $12(40.0 \%)$ in control group stated that knowing what to do in an emergency would have made a difference to their situation, while the participants who were lacking of knowledge about $11(36.7 \%)$ in the study group versus $18(60.0 \%)$ in control group, the patient outcomes can be improved by providing patients with information about the action plan during a cardiac emergency.

Methods used to control symptoms after cardiac episodes (Level 5), complementary therapies and other healing practices may contribute to the reduction of stress and other lifestyle practices that predispose to cardiovascular disease. Although (16) $53.3 \%$ of the sample in the study group versus (19) $63.3 \%$ in the control group used alternative medicine, they also acknowledged the use of other means to cope with the symptoms of ACS as $3(10.0 \%)$ in the study versus $5(16.7 \%)$ in the control group used mind-body intervention, while $3(10.0 \%)$ in the study versus $4(13.3 \%)$ in the control group used biologically based treatments, and $8(26.7 \%)$ in the study versus $2(6.7 \%)$ in the control group did not used any of them.

Table (4) : illustrates the pain or discomfort during an emergency situation, it was found $26(86.7 \%)$ of the sample in the study group versus $19(63.3 \%)$ of the control group who identified that their area of pain or discomfort was the chest, and $4(13.3 \%)$ of the study group versus $6(20.0 \%)$ in control group experienced the pain or discomfort in the arms or shoulders, pain was in the back in $5(16.7 \%)$ of the control group, while it was neglected by the patient in study group with statistical significance difference $(\mathrm{P}=0.039 *)$.

Atypical symptoms of ACS which the participants experienced, Heart or epigastria discomfort was found to be in $19(63.3 \%)$ of the sample in the study group versus 15 (50.0\% in the control group, while shortness of breath was found in $7(23.3 \%)$ of the sample of the study group versus $13(43.3 \%)$ in the control group, and sweating was found to be in 4 $(13.3 \%)$ of the study group versus $2(6.7 \%)$ in the control group show.

As for the signs and symptoms related to cardiac problems, the participants were asked if they were able to relate their signs and symptoms to a cardiac problem to determine the patients' level of knowledge about ACS. Of the 30 participants only 14 $(46.7 \%)$ were able to relate their experiences to cardiac problems in the study group versus 16 $(53.3 \%)$ in control group said yes, while $16(53.3 \%)$ failed to make any connection between their signs and symptoms to cardiac problems in study group versus $14(46.7 \%)$ in control group said no. 
Regarding the activity during pain onset, according to the study results it was found that $8(26.7 \%)$ of the study sample were working versus $5(16.7 \%)$ in control group, while $22(73.3 \%)$ in study group were resting versus $25(83.3 \%)$ in control group when they experienced ACS.

Table (5): demonstrates age of the studied nurses, it ranged from 22.0-32.0 years with mean of $25.75 \pm$ 3.14. Moreover, $75 \%$ of them were married, and $91.7 \%$ had diplom degree and $8.3 \%$ were Institute (Practical or technical Nurses (graduated from secondary or 2 or 3 years after), Professional Nurses (university graduates) had diploma, or bachelor degree.

Table (6) : Shows comparison between nurses knowledge about caring practices in nursing competences for patients with acute coronary syndrome There were no statistical significant differences between both groups according to practice need required by the patient heart when he entered $12(100 \%)$ in pre and posttest while in caring practice to improve patient conditions10 (83.3\%) in pre and $12(100 \%)$ in the post-test.

Table (7) : Shows comparison between nurses' knowledge about clinical judgment in nursing competences, it was noticed no statistical significant difference between both groups according to nurses Knowledge for implementation of patient order in pretest $(12(100 \%)$ in and after application of training In pretest and posttest, program in present policy in critical care were (1) $8.3 \%$ in pre while (12)100.0\% in post with $\mathrm{P}=0.001$ *

Table (8) : Shows comparison between nurses' knowledge about advocacy moral agency in nursing competences it was noticed no statistical significant difference between both groups according to patient privacy $6(50.0 \%)$ in pretest while $9(75.0 \%)$, which health education for patient $9(75.0 \%)$ in pretest said yes while $3(25 \%)$ said no while $12(100 \%)$ in posttest said yes.

Table (9) : Shows rating score for patients characteristics, it was noticed that most stability of patient in study group with n.18 (60\%) while n.12(40 $\%)$ with least stability with $(\mathrm{p}=0.004 *)$, that most resiliency of patient in study group with n.20 (66.7\%) while n.10(33.3\%) with least resiliency with $\left(\mathrm{p}=0.000^{*}\right)$, that most resource availability of patient in study group with n.25(83.3\%) while n.5(16.7\%) with least resource availability with $(\mathrm{p}=0.000 *)$

Table (10): Shows rating score for nursing competency, it was noticed that most advocacy and moral agency of nurses in post-test with n.11 (91.7\%) while n.1 (8.3\%) with least advocacy and moral agency with $(\mathrm{p}=0.001 *)$, that most caring practice nurses in post-test with n. $10(83.3 \%)$ while n.2 (16.7 $\%)$ with least caring practice with $\left(\mathrm{p}=0.013^{*}\right)$, that most clinical judgment of nurses in post-test with n.7 $(58.3 \%)$ while n.1 (8.3 \%) with least clinical judgment with $(\mathrm{p}=0.030 *)$

\section{Discussion}

American Association of Critical Nursing Synergy Model for Patient Care, developed by a group representing the American Association of Critical Nursing, is a patient-centered model that is focused on the needs of the patient, the competencies of the nurse, and the Synergy created when those needs and competencies match (Smith et al., 2013)

Critical care nursing is a demanding specialty that requires advanced knowledge of physiology and highly technological interventions. Nurses care for critically ill patients in intensive care units (ICUs) and progressive care units. Because the acuity of hospitalized patients has increased, some authors claim that all hospital nursing care has become critical care Patients in critical care units are the most seriously ill and injured among all hospitalized patients (Kaplow et al., 2005).

Various assumptions regarding nurses, patients and families guide the Synergy Model Patients are biological, psychological, social, and spiritual who present at a particular developmental stage. The whole patient (body, mind and spirit) must be considered the patient, family and community all contribute to providing a context for the nurse-patient relationship, Patients can be described by a number of characteristics. All characteristics are connected and contribute to each other. Characteristics cannot be looked at in isolation; similarly, nurses can be described on a number of dimensions. The interrelated dimensions paint a profile of the nurse, a goal of nursing is to restore a patient to an optimal level of wellness as defined by the patient. (Hardin, 2009).

The current studies showed that most of patients in the age group 55and 60 years and were patients males with myocardial infarction This results supported by the study done by (Funk et al., 2009). found that, most MI occur in people over 55, and become more common with increasing age.

Hypertension is one of the very important factors that can be controlled adequately by diet, modification of life style. In the current study hypertension seems to be the most common associated risk factors in acute coronary syndrome this study agree with the study done by (Wolf-Maier et al.,2003) and(Gupta, 2004). Are found that hypertension prevalence in Spain to be approximately in general population and hypertension is responsible for patient with coronary heart disease deaths in India. Diabetes mellitus in the present study constituted of acute coronary syndrome 
while disagree with the study done by (Kahn \& Brener, 2012). Showing that diabetic patients hospitalized with STEMI are older, more often females, more likely to present with a prior myocardial infarction (MI).The present study show most commonly types of acute coronary Syndrome(myocardial infarction and unstable angina)in line with the study done by (Omar, 2007). Showed that total patients presenting with acute coronary syndromes with ST segment elevation myocardial infarction \&quarter patients with non ST segment elevation myocardial infarction and unstable angina.

Patient stability the current study showed that highly significance difference in both (consideration of death, thoughts of experiencing of chest pain/discomfort) in both study and control group this is agree with the study done by (Hardin et al., 2007) show that had (considered death as a possible outcome during the acute coronary syndrome and experience chest pain) is highly significance In study and control group So the public need to be educate on the risk factors of acute coronary syndrome and take precautions to prevent the occurrence. (Devon and Zerwic, 2004) agree with me which Show that highlights the public should be informed about the other atypical symptoms of acute coronary syndrome and therefore should not delay seeking treatment because they have no symptoms of chest pain or discomfort. The current study show that patient for resiliency that highly significance difference in according to ability to bear chest pain this is in line with the study done by (Devon et al., 2005) presents in study of total patient approximately half coped to bear chest pain. patient of resource availability Patient knowledge of illness the current study showed that significance difference in both study and control group had identified that their area of pain or discomfort was in the chest this is in line with the study done by (Ryan et al., 2005) present study of total patient had identified that their area of pain or discomfort was in the chest.

Nurse competencies of knowledge about advocacy and moral agency the current study show that no significance difference between nurse knowledge in pre and posttest in training program in advocacy and moral agency causes lack of nurses knowledge; nurses' exhaustion and prolonged working hours due to lack of rewarding system and prolonged working hours this is line with the study done by (Rivet, 2012) mentioned that rewarding system and prolonged working hours it is essential to provide frequent education on infrequently performed protocols to ensure staff competence and comfort, as well as patient safety and rights.
Regard nurse knowledge about clinical judgment the current study showed that highly significance difference between nurse knowledge in pre and posttest in training program according to policy in critical care this is disagree with the study done by (Hardin \& Kaplow, 2005) show that synergy model is extremely effective in articulating the important role that professional nursing plays in the health care system and when facilitated by the organization standard defines the impact professional nursing can have not only on patient outcomes.

Nurses knowledge about caring practice the current study show that no significance difference between nurse knowledge in pre and posttest in training program in caring practice this is disagree with the study done by (Hardin \& Kaplow, 2005) show that work of nurse by synergy model framework and leads to the ability to capitalize on individual strengths of nurses required by the patient it has been established that nursing practice based on levels of expertise.

\section{Conclusion}

Efficient nursing management in the initial hours after chest pain onset and throughout subsequent care are important, Applying the Synergy model for patient care and comprehensive care help to reduce patient complication and improve outcomes.

\section{Recommendations}

Based on the finding of the current study, the follow recommendations are suggested

- Patients presenting with acute cardiac conditions should be managed by a specialist, multidisciplinary cardiac team and have access to key cardiac investigations and interventions by using the Synergy model, at all times.

- Nurses should be encouraged to attend specific meeting as workshop Provide the Emergency department with special unit for caring patient with acute coronary syndrome.

- Equip the coronary care unit with simple illustrated apply of Synergy model for caring of patient in critical care unit.

- Develop educational program for nursing staff caring for patient with Acute Coronary Syndrome.

- Repeat this research on a large sample size and different governmental hospital for generalization.

- Further researches are recommended to develop Synergy model tools in nursing guidelines for acute coronary syndrome patient. 


\section{Limitation of the study}

There were some Limitations facing the researcher during the period of data collection, it includes following point:-

There is no standard of care provided for patient in coronary care unit, * Lack of nurse's knowledge; nurses' exhaustion, prolonged working hours and most of them had diploma.

\section{References}

1. Bhardwaj R., Kandoria A., Marwah R., Vaidya P., Singh B., Dhiman P., Sharma A., (2010): Prevalence, Awareness and Control of Hypertension in Rural Communities of Himachal Pradesh JAPI; Vol.58. pp. 423-425.

2. Devon H., (2005): chest pain associated symptoms of acute coronary syndromes. Journal of cardiovascular nursing, Vol.20 (4):pp.232238.

3. DevonHA, Z., (2004) : Differences in the symptoms associated with Unstable angina and myocardial infarction. Progressive cardiovascular nursing, Vol. 19(1):pp.6-11

4. Funk M., Winkler C., Fashjian M., Fennie K., Stephens K., May J., \& Drew B., (2009): Assessment of Risk for a Serious Cardiovascular Event American Heart Association, (Circulation.;120:S481.

5. Gupta R., Trends, (2004) : in hypertension epidemiology in India. Journal of Human Hypertension;Vol. 18:pp73-78.

6. Hardin S., (2007): Indianapolis, IN: Sigma Theta Tau Critical care nursing: synergy for optimal outcomes.1st ed. Sudbury: Jones \& Bartlett Learning;

7. KahnM B., (2012) : Association of diabetes with increased all-cause mortality following primary percutaneous coronary intervention for ST-segment elevation myocardial infarction in the contemporary era. DiabVasc Dis Res 2012; Vol.9.:pp3-9.

8. Hardin S., \&Kaplow R., (2005) : Critical care nursing: synergy for optimal outcomes. 1st ed. Sudbury: Jones \& Bartlett Learning;

9. Kokiwar P., Gupta S., Durge P., (2012): Prevalence of Hypertension in a Rural Community of Central India. J A P I; Vol.60:pp.26-29

10. Kaplow R., Hardin S., (2005) : Critical care nursing: synergy for optimal outcomes. 1st ed. Sudbury: Jones \& Bartlett Learning;

11. Mohammed M., (2010) : knowledge, practices and attitude of nurse's toward universal precaution in outpatient clinics Assiut University
Hospital, thesis of master degree in community health nursing Assuit University

12. Omar S., \& Mohammed Salem (2007): M.B.B.Ch. Resident of Internal Medicine, Sohage University Hospital.

13. Rivet C., (2012) : Desensitization training CCU RNs run aspirin desensitization project at The Miriam Hospital in Providence, J Am CollCardiol;Vol. 30:pp.1606-1610.

14. Smith A., Larew C., (2013) : AACN Synergy Model for Patient Care. Aliso Viejo, CA: American Association of Critical-Care Nurses; available http://www.aacn.org/wd/certifications/content/sy nmodel.pcms?menu=certificatin

15. Wolf-Maier K., Cooper R., Banegas J., Giampaoli S., Hense H., Joffres M., (2003): Hypertension prevalence and blood pressure levels in 6 European. 